I 


\section{OT 32}

Operator Theory: Advances and Applications

Vol. 32

\section{Editor:}

\section{Gohberg}

Tel Aviv University

Ramat Aviv, Israel

Editorial Office:

School of Mathematical Sciences

Tel Aviv University

Ramat Aviv, Israel

Editorial Board:
A. Atzmon (Tel Aviv)
J. A. Ball (Blacksburg)
M. A. Kaashoek (Amsterdam)
L. de Branges (West Lafayette)
T. Kailath (Stanford)
K. Clancey (Athens, USA)
H. G. Kaper (Argonne)
L. A. Coburn (Buffalo)
S.T. Kuroda (Tokyo)
R. G. Douglas (Stony Brook)
P. Lancaster (Calgary)
H. Dym (Rehovot)
L. E. Lerer (Haifa)
A. Dynin (Columbus)
E. Meister (Darmstadt)
B. Mityagin (Columbus)
P. A. Fillmore (Halifax)
J. D. Pincus (Stony Brook)
C. Foias (Bloomington)
M. Rosenblum (Charlottesville)
P. A. Fuhrmann (Beer Sheva)
J. Rovnyak (Charlottesville)
S. Goldberg (College Park)
D. E. Sarason (Berkeley)
B. Gramsch (Mainz)
H. Widom (Santa Cruz)
J. A. Helton (La Jolla)
D. Xia (Nashville)
D. Herrero (Tempe)

Honorary and Advisory

Editorial Board:

P. R. Halmos (Santa Clara)

S. G. Mikhlin (Leningrad)

T. Kato (Berkeley)

R. Phillips (Stanford)

P. D. Lax (New York)

B. Sz.-Nagy (Szeged)

M. S. Livsic (Beer Sheva)

Springer Basel AG 


\section{Topics in Operator Theory Constantin Apostol Memorial Issue}

Edited by

I. Gohberg 
Volume Editorial Office:

Raymond and Beverly Sackler Faculty of Exact Sciences

School of Mathematical Sciences

Tel Aviv University

Tel Aviv, Israel

\section{CIP-Titelaufnahme der Deutschen Bibliothek}

Topics in operator theory: Constantin Apostol memorial issue / ed. by I. Gohberg. - Basel ; Boston ; Berlin : Birkhäuser, 1988

(Operator theory ; Vol. 32)

NE: Gochberg, Izrail' [Hrsg.]; Apostol, Constantin: Festschrift; GT

This work is subject to copyright. All rights are reserved, whether the whole or part of the material is concerned, specifically those of translation, reprinting, re-use of illustrations, broadcasting, reproduction by photocopying machine or similar means, and storage in data banks. Under $\S 54$ of the German Copyright Law where copies are made for other than private use a fee is payable to »Verwertungsgesellschaft Wort«, Munich. 


\section{TABLE OF CONTENTS}

From the Editor.............. VII

D.A. Herrero: In Memory of

Constantin Apostol.............. 1

List of Publications of

Constantin Apostol...............

C. Apostol: On the Spectral

Equivalence of Operators........... 15

BEN-ARTZI, A.

Fredholm properties of band

GOHBERG, I.

matrices and dichotomy............

BERCOVICI, $\mathrm{H}$. CONWAY, J.B.

CEAUȘESCU, $Z$. SUCIU, I.

DAVIDSON, K.R.

FEEMAN, T.G.

SHIELDS, A.L.

FOIAS, C.

TANNENBAUM, A.

HERRERO, D.A.

TAYLOR, T.J.

WANG, Z.Y.

LARSON, D.R.

SOLEL, B.

RAN, A.C.M.

RODMAN, L.

SALINAS, N.

VASILESCU, F.-H.

VOICULESCU, D.
A note on the algebra generated

by a subnormal operator............ 53

Extreme points in the set of

contractive intertwining dilations....

Extreme points in quotients

of operator algebras...............

On the four block problem, I........

Variation of the point spectrum

under compact perturbations..........

Bimodules of nest subalgebras

of von Neumann algebras ........... 159

Stability of invariant

Lagrangian subspaces I............ 181

Products of kernel functions

and module tensor products......... 219

Spectral capacities in

quotient Fréchet spaces........... 243

A note on quasidiagonal operators..... 265 


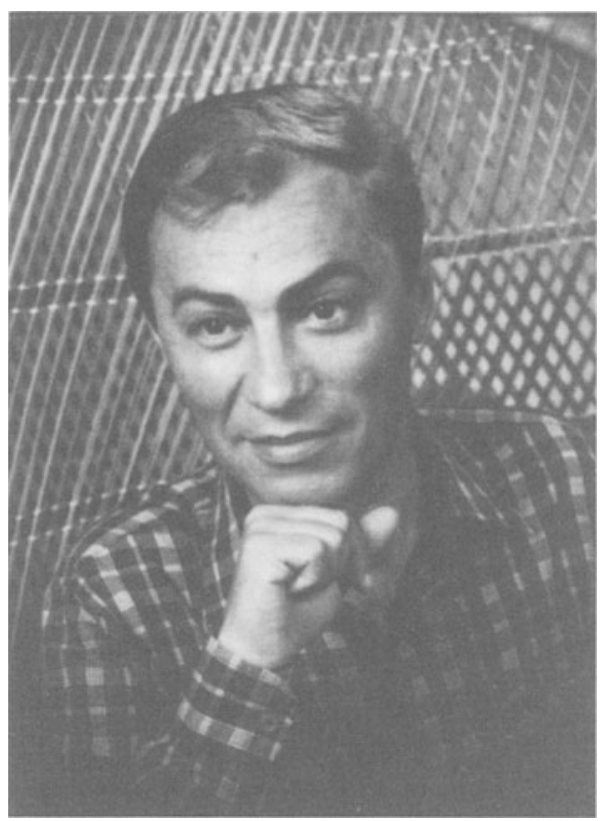

CONSTANTINAPOSTOL (1936-1987) 
FROM THE EDITOR

Autum 1985 Constantin Apostol became interested in the problem of local and global spectral equivalence. He soon produced a manuscript with interesting results. Who could imagine that this manuscript was to be a draft of his last paper, and it is with this paper that this Memorial issue begins. The final touches in the preparation of this paper for publication were done by Domingo Herrero; the author was already in hospital.

Constantin Apostol will be remembered as an outstanding expert in operator theory, in which area he made very important and deep contributions. His friends and colleagues dedicate this volume to his memory.

Hearty thanks are due to Domingo Herrero for his assistance in preparing this volume.

I. Gohberg 